\title{
Stakeholder Participation in Natura 2000 Management Program: Case Study of Slovenia
}

\author{
Tomislav Laktić ${ }^{1}$ and Špela Pezdevšek Malovrh ${ }^{2, *}$ \\ 1 Water and Investments Directorate, Cohesion Policy Division, Ministry of the Environment and Spatial \\ Planning, 1000 Ljubljana, Slovenia; tomislav.laktic@gov.si \\ 2 Department of Forestry and Renewable Forest Resources, Biotechnical Faculty, University of Ljubljana, \\ 1000 Ljubljana, Slovenia \\ * $\quad$ Correspondence: spela.pezdevsekmalovrh@bf.uni-lj.si; Tel.: +386-1320-3522
}

Received: 23 August 2018; Accepted: 24 September 2018; Published: 26 September 2018

\begin{abstract}
The Natura 2000 network, which is one of the largest networks of protected areas in the world, is the core pillar in the European Union's biodiversity conservation policy. To achieve the national enforcement of Natura 2000 and to overcome implementation problems, effective policy measures are needed, and participation among different stakeholders is required. The aim of this paper was to evaluate the process of formulation of the Natura 2000 Management Program (2015-2020) in Slovenia based on a set of criteria and indicators for the evaluation of a participatory process, and to present the differences between the stakeholders' evaluations according to their role in the implementation process. For that purpose, stakeholders were divided into two groups-stakeholders from project partner's institution, and others. The research was done in two steps: First, in-depth semi-structured interviews with 17 representatives of the key stakeholders' institutions or organizations that were involved in the formulation of the Natura 2000 Management Program were carried out; in the second, a survey with 266 stakeholders involved in the formulation and decision-making process was conducted. Overall, the results show that the participatory process was well organized, independent and fair; however, not all of the requisite conditions for successful participation were fulfilled, as was shown with the sub-criteria of transparency. The only difference between the groups exists in the evaluations of the sub-criteria transparency of the process. The group of stakeholders from the project's partner institutions were more satisfied with the transparency of the process, as the average value was 3.36, compared to the others where the average value of satisfaction was 2.80 . This indicates the need for an improved, novel, and innovative approach that leads to multi-level governance.
\end{abstract}

Keywords: participation; Natura 2000; management program; stakeholders; Slovenia

\section{Introduction}

The Natura 2000 network, which encompasses the Birds and Habitats Directive of the European Union (hereafter EU) (Directive 79/409/European Economic Community, amended as 2009/147/European Commission and Directive 92/43/European Economic Community, respectively), is the core pillar in the EU's biodiversity conservation policy [1,2], and is one of the largest networks of protected areas in the world [3,4]. These directives are legally binding; thus, individual member states had to transpose them into their national legislation [1]. Moreover, the EU member states were relatively free to choose the most suitable means to achieve the main goals of the directives, and to design the implementation process and the management of the protected sites in line with the overall objectives of national policies. Thus, countries have adopted different, often top-down and science driven approaches, with widely varying degrees of participatory processes [5]. 
The implementation of the objectives of the Birds and Habitats Directives in the national legislation leads to changes in national legislation. These changes are based on the changing relationship in decision making at the national level, with the inclusion of new stakeholders in the national system of nature protection (which also causes changes in the traditional roles of the stakeholders) [6,7]. Non-governmental organizations (hereafter NGOs) in the field of nature protection and private forest owners have been given the opportunity for equal participation as governmental stakeholders in decision making in the process of implementation of Natura 2000 [3,7-10].

Several authors have recently studied the implementation processes and issues that have arisen in the national transposition and establishment of Natura 2000. According to [11], the implementation of Natura 2000 in various EU member states is linked to multiple processes at different policy levels, and depends on case-specific interplay. Consequently, a large diversity of implementation approaches has been adopted, and can be seen as advantageous as it enables learning for improved future functioning [12]. To improve the practical implementation in most countries, the authors suggest the need for more communication and participation with stakeholders [13], the importance of inter-sectoral cooperation $[8,14]$, the need for co-responsibility of all relevant stakeholders who are involved in the process [15], and an awareness of the socio-economic and cultural contexts in which conservation planning takes place [16]. Moreover, research also deals with challenges for the implementation of Natura 2000 in forests. According to [17], the main challenges are related to balancing biodiversity conservation and timber production, integrating nature conservation and local stakeholders' demands, the development of an effective and accepted funding scheme for the implementation of Natura 2000 in forests, and how to integrate nature conservation policies with forest and other land use sector policies. However, the implementation process also has obstacles connected to poor participation and negative perceptions of stakeholders, inflexible regulations, and limited concern to local context $[8,18]$. In addition, the implementation process of Natura 2000 very often became a complex and lengthy undertaking, causing a variety of policy and management conflicts [19-21]. These conflicts were related to contradictory stakeholder's interests, values, and perceptions, as well as to different and competing land use principles [22]. To prevent further conflicts and to strengthen the implementation process, the involvement of and cooperation with various stakeholders, as well as stakeholder participation and coordination between institutions and organizations, have been stressed as important tools to increase the acceptance of Natura 2000 [23,24].

In Slovenia, the designation of Natura 2000 sites was a requirement for accession to the EU, so the majority of sites were designated by 2004. Therefore, in 2002, the Government launched the project Natura 2000 to elaborate a communication strategy and to present the Natura 2000 contents to relevant stakeholders. Therefore, Slovenia has chosen to develop an overall national document "Operational program-Natura 2000 Management Program", hereafter PUN. The Government of the Republic of Slovenia adopted in 2007, the Operational programme-Natura 2000 Management Programme for the 2007-2013 (hereafter PUN 2007-2013) and the second Natura 2000 Management Programme for the 2015-2020 (hereafter PUN 2015-2020), which outlines management requirements for sites, and which need to be incorporated in other planning documents that already regulate the use of natural resources, such as forest management plans [25]. Since the request of the EU, the Natura 2000 network in Slovenia covers 37.9\% of the national territory [26], of which almost 70\% are forests, followed by $23 \%$ of agricultural land and slightly less than $13 \%$ of different types of permanent grassland [27]. The Ministry of Environment and Spatial Planning (hereafter MESP) and Ministry of Agriculture, Forestry and Food (hereafter MAFF) are responsible for ensuring that management measures are incorporated in the management plans, and are implemented in the field. The overall approach in Slovenia for management plans related to forestry, hunting, and fishing is that the responsible institutions draft a plan and provide an opportunity for consultation among the stakeholders.

Slovenia is among the most forested countries in Europe; 1,184,369 ha of forests cover more than a half of the country's territory (forestation amounts to $58.4 \%$ ). Notably, $76 \%$ of forests in Slovenia are private property, while $24 \%$ are public (owned by the state or communities). Larger and rarely 
fragmented estates of state-owned forests enable good professional management. Private forest estates are small, with an average area of only $3 \mathrm{ha}$, and even these are further fragmented into several separate plots. For the great majority of these estates, forests are not of economic interest. There are already 313,000 (461,000 when including co-owners) forest owners in Slovenia. The major fragmentation of forest property and the number of forest owners and co-owners present a serious obstacle to professional work in private forests, to optimal timber production, and to the utilization of forest potential. In Slovenia $58.4 \%$ of forest owners have a forest property smaller than 1 ha, while $41 \%$ of forest owners have a forest property between 1 and 30 ha. Less than $1 \%$ of forest owners have a forest property bigger than 30 ha [28-30].

Stakeholders can participate in the formulation and implementation of the Natura 2000 in different ways, e.g., from written consultation through steering committees and advisory boards, to discussion forums and workshops [31,32], but there are no specific recommendations about participation. Consequently, the degree of participation varies among countries according to national characteristics and peculiarities [33]. Moreover, the countries also differ greatly with regard to the levels of stakeholder involvement, including at what stage stakeholders were informed or involved (before or after site designation), the level of involvement (only information or negotiation), as well as which interest groups were consulted the most (nature conservation and/or landowners and users) [17].

However, the overall impression is that in the beginning of the domestic implementation process, public authorities in most EU countries did not involve landowners, whereas conservation experts were involved to provide their substantive technical knowledge and information about habitats and species which administrations were partially lacking. This can be largely explained by the fact that the designation of Natura 2000 sites had to be based solely on scientific criteria rooted in conservation biology, as stipulated in the EU's Habitats and Birds Directives. Site designation was mostly done without any consultation with, or informing of, landowners. With the progression from site designation to the current phase of management planning and practical measures, there is growing evidence of more dialogue and cooperation between nature conservation authorities and environmental groups on the one side, and agricultural and forestry authorities and land users' groups on the other [17].

For example, in the process of implementation of the Natura 2000 network in Slovakia, public stakeholders were involved through co-decision, while the other categories of stakeholders were involved at different levels (collaboration or information), demonstrating a willingness to follow a participative approach [34].

Based on the evaluation criteria for an effective participatory process [35], the objectives of the paper are to present how stakeholders' involvement and participation have evolved in the process of formulation of the Natura 2000 Management Program (2015-2020) in Slovenia, and to present the differences between stakeholders' evaluations of the participatory process according to their role (stakeholders from project partner's institution and other stakeholders) in the implementation process. The usefulness of this research is to improve the participatory process in future PUN and other nature conservation and forest-related programs.

\section{Conceptual Framework of the Study}

\subsection{Natura 2000 Network and Participatory Process in Slovenia}

In Slovenia, it is possible to identify three main separate stages in the implementation of the Natura 2000 network and the participation of stakeholders:

1. The first one corresponding to the designation of Natura 2000 network starting at the end of 2002 and ending in May 2004, with the entry of Slovenia into the EU. In 2002, the Government launched the project Natura 2000 and established two working groups: The first for communication and the second as an expert-technical group. Expert-technical working group was responsible for the expert preparation of the designation process, autonomous in its co-operation with external expert partners and was responsible for commissioning expert evaluation from NGOs and other 
sources of expert knowledge. In this phase, the efforts of the communication working group (Three institutions were partners in communication group, namely the Institute of the Republic of Slovenia for Nature Conservation (hereafter IRSNC), Slovenian Forest Service (hereafter SFS) and the Chamber of Agriculture and Forestry of Slovenia (hereafter CAFS).) were focused on the elaboration of a communication strategy with different key stakeholders (local authorities, land owners, the broad public etc.), but because of a lack of time, this communication was more focused on informing them about the possibilities, expected problems, and restrictions than on actually including them in the process. Consequently, broader interests were not expressed, and contra interests were not clearly articulated in the stage of preparing a list of potential protected areas. Hence, conflicts have been very limited in this phase [25,36-39]. Therefore, the process of implementation of the Natura 2000 (designating the sites) was highly centralized and top-down orientated [36].

2. The second one, starting in 2005 and ending in 2007, coincided with the elaboration of the Operational programme-Natura 2000 Management Programme for the 2007-2013. The PUN 2007-2013 designated protection objectives and measures at Natura 2000 sites, as well as defining the competent sectors and responsible implementers of these protection measures [40]. A further goal in this respect was to enable horizontal links with strategic plans and development programs. These activities took place within the LIFE pilot project "Natura 2000 in Slovenia-Management Models and Information System" at five different Natura 2000 sites, by laying the theoretical foundations for the elaboration of PUN. The coordinator of the project was the IRSNC. Numerous workshops in cooperation with representatives from the hunting, forestry, agriculture, fisheries, water management sectors, and local community representatives were held to provide systemic solutions for efficient and sustainable management of Natura 2000 sites in Slovenia. The first draft of PUN 2007-2013 was presented to research and education institutions, nature conservation institutions, and managers of protected areas for modification of objectives and measures. The final draft of PUN 2007-2013 was then presented during two workshops to local authorities, NGOs, and public services, before the official adoption by the Government in the end of 2007 [40].

It can be concluded that the process of elaborating the PUN 2007-2013 was highly centralized and top-down oriented, with the beginnings of inclusiveness of stakeholders from public services who are responsible for the implementation of Natura 2000 measures.

3. The third one starting at 2012 and ending at 2015 (Figure 1) corresponded to the elaboration of the PUN 2015-2020, where the main focus was on preparation of detailed conservation objectives for Natura 2000 sites, measures for achieving conservation objectives, and the institutions responsible for their implementation. The activities necessary for the adoption of this operational program were supported by the LIFE ${ }^{+}$project, whose coordinator was the MESP and whose associated partners were the IRSNC, the SFS, Fisheries Research Institute of the Republic of Slovenia (hereafter FRIS), Institute for Water of the Republic of Slovenia (hereafter IWRS), and the CAFS as a representative of agriculture and forest land owners. As the initial top-down implementation in former phases provoked severe resistance from different stakeholders, mostly land and forest owners, changes towards a participatory governance mode occurred in this phase, which enabled participatory elements. Therefore, the communication plan included stakeholder analysis, different ways of involving stakeholders from different sectors in each phase with the aim of giving information, as well as consultation and participatory decision-making regarding the management of Natura 2000 sites in the future. The stakeholders could have influenced the content of the management program of Natura 2000. However the aim of PUN was not to change the boundaries of Natura 2000 in Slovenia, and in addition, stakeholders did not have influence over the defined boundaries of Natura 2000. The institutions responsible for the content of PUN 2015-2020 were IRSNC and MESP. They made decisions regarding which comments were to be accepted, and which ones rejected. The individual detailed protection objectives and measures were the main part of stakeholders' comments, for which the criteria for the acceptance of comments or arguments were based on scientific and expert knowledge. 


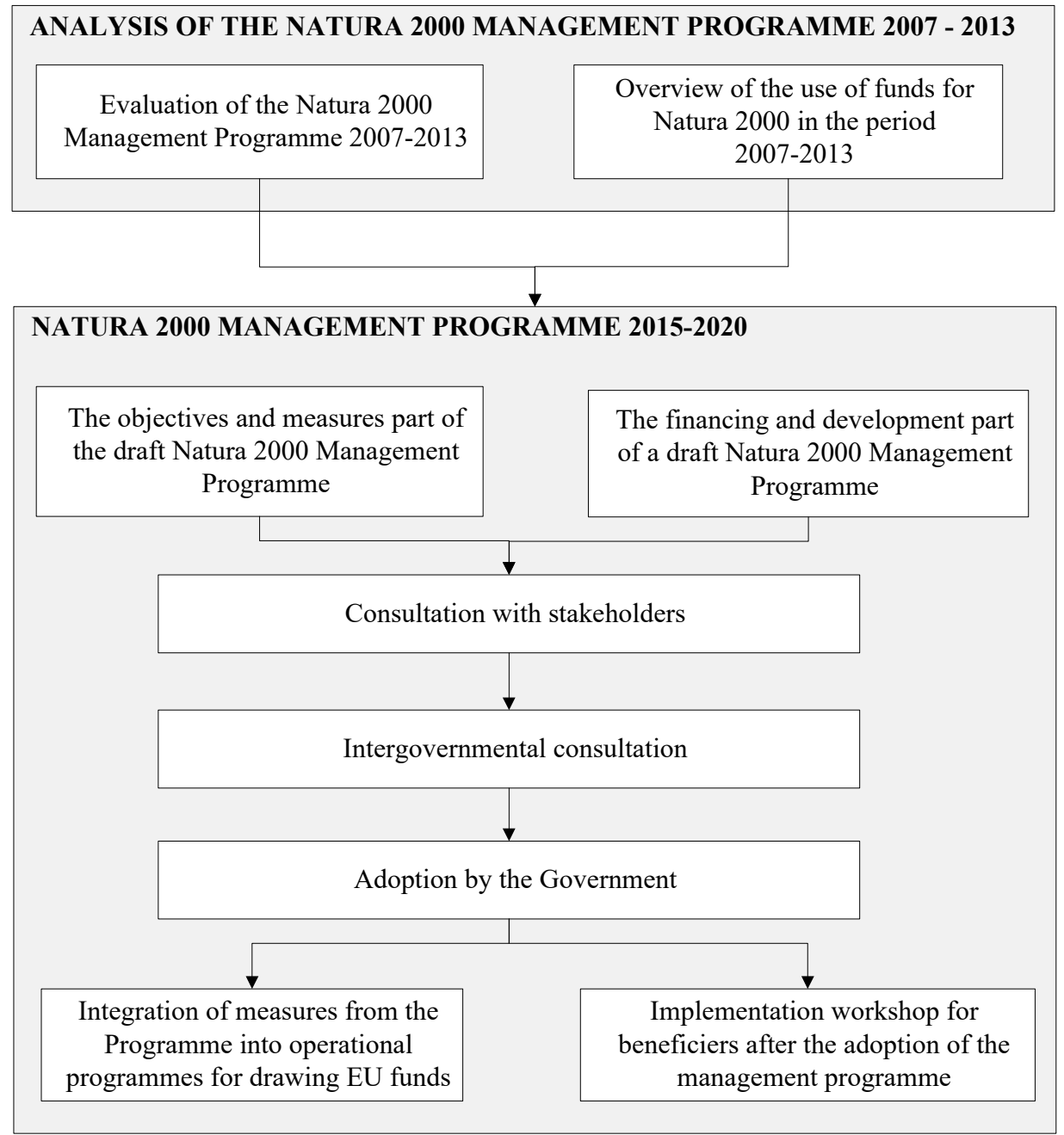

Figure 1. The formulation process of the PUN 2015-2020 in Slovenia.

The first draft of PUN 2015-2020 was prepared by IRSNC in cooperation with project partners, researchers, and experts on plant and animal species, during 77 workshops. The draft was discussed in 6 targeted roundtables (public meetings) in different parts of Slovenia. The amended draft of PUN 2015-2020 was a subject of intergovernmental consultation, which consisted of consultation meetings with all ministries and their public bodies, as well as the Chamber of Commerce. The PUN 2015-2020 was adopted in April 2015. After the adoption, eight workshops were organized for beneficiaries-including workshops with presentations of beneficiaries working on the elaboration of management programme for a wider audience of other colleagues (public servants) from public services, and also the private sector, especially to those responsible for future implementation of measures from the programme-and managers of nature parks to spread awareness about PUN. In the elaboration of the new management program, despite the aforementioned adopted approach, there was still a top-down approach; there was a switch from more communication with stakeholders to consultation with key stakeholders [37].

When Natura 2000 was implemented, the Government of the Republic of Slovenia asserted that no additional costs for its implementation, maintenance, and management would be needed. The funding needed for Natura 2000 was predicted to come only from EU. Consequently, no financial compensation for restrictions to landowner's activities under Natura 2000 were predicted in PUN. However, a budgetary fund, the so called Forest Fund, was established (Article 33) based on the changes in the organizational structure of the state forest management and the adoption of the new Act in 2016, the "Management of State Forest Act". The Forest Fund is financed by the income of the 
state forest management. The assets of forest funds are intended to also cover measures in the area of Natura 2000 in private forests in accordance with the PUN 2015-2020 and program investments in forests, established on the basis of the National Forest Program prepared by SFS in accordance with the Forest Act (Management of State Forests Act, Official gazette of Republic of Slovenia number 9/2016) [41].

\subsection{Theoretical Context}

Claims for participation are often made in terms of democracy. The basic principles that characterize democracy, and which are recognized in most democratic constitutions, are "popular control" and "political equality". This view, often referred to as the liberal constitutionalism of political participation [42], is based on the idea that a liberal constitution should facilitate pluralistic politics, i.e., politics that acknowledge various interests in society [33]. Participatory approach in this context would imply equal participation of different interest groups, and is often called "stakeholders' participation". From a democratic point of view, the essential question with regard to this kind of stakeholders' participation approach is whether it manages to include all the different interests in a fair and legitimate way; according to [43] "public participation" encompasses a group of procedures designed to consult, involve and inform the public to allow those affected by a decision to have an input into that decision.

The extent to which participatory processes fulfill the expectations is nevertheless highly dependent on how stakeholders are involved in the process. Instructions for a successful participatory process do not exist, because the form and structure of the process can vary widely, depending on e.g., the policy in consideration, the institutional context, and the operational environment. Researchers have, however, suggested some general criteria for an effective participatory process, based either on theoretical analysis (see e.g., [35,44,45]) or empirical studies in a particular context (see e.g., [46-48]).

In our study, the set of criteria outlined by [35] was selected as the basis for the evaluation of the participatory process (Table 1). The authors divided the evaluation criteria into acceptance criteria (including representativeness, independence, influence and transparency), which are related to the effective construction and implementation of a procedure, and process criteria (including resource accessibility, cost-effectiveness and task definition), which are related to the potential acceptance of a procedure.

The authors agree that an effective participation process should be inclusive and representative, meaning that participation should comprise, from the very beginning, a broadly relevant and representative sample of the population of the affected public, and that no stakeholders who are willing to participate be deliberately excluded from the process [45,47].

Another key characteristic for genuine participation is that the participation process should be conducted in an independent, unbiased way, which means that management and facilitation of the participation process should be completely independent from all affected interests, and should be fair. On a general level, fairness stipulates that all stakeholders are equally able to express opinions, defend them, and request evidence and justification from other stakeholders. One of the main complaints about the participation processes is that they have often been perceived as ineffectual, simply being used to legitimize decisions or give an appearance of consultation without there being any intent of acting on recommendations [35]. One approach that might lead to fulfilling these criteria is to ensure that stakeholders have an influence on the final decision, so that the output of the process has a genuine impact on policy. The key element defining stakeholder participation is the will of the stakeholders to influence the policy. The point of a participatory process is also to obtain the opinions and perceptions of stakeholders. Sometimes, according to [45], capacity building can be a more enduring and widespread outcome of the participatory process than an actual agreement. The influence of stakeholders depends on their degree of involvement. According to [49], it is possible to divide the degree of involvement into five degrees of participation, with different possibilities for stakeholders to influence the outcome: (a) Information: Explanation of the project to the stakeholders; (b) Consultation: 
Presentation of the project to stakeholders, collection of their suggestions, and then decision making with or without taking stakeholders' input into account; (c) Collaboration: Presentation of the project to stakeholders, collection of their suggestions, and then decision making, taking stakeholders' input into account; (d) Co-decision: Cooperation with stakeholders towards an agreement for solution and implementation; (e) Empowerment: Delegation of decision-making over project development and implementation to the stakeholders. Finding a jointly acceptable strategy and course of action is important, if the goal is to commit stakeholders to the implementation of the policy/program.

Table 1. Evaluation Criteria and Indicators for an Effective Participatory Process.

\begin{tabular}{|c|c|c|}
\hline Criteria & Sub-Criteria & Related Indicators \\
\hline \multirow{12}{*}{ Acceptance criteria } & \multirow{5}{*}{ Representativeness } & Early involvement \\
\hline & & Relevance of the involved stakeholders \\
\hline & & A broad range of stakeholders involved \\
\hline & & $\begin{array}{l}\text { No stakeholder who is willing to participate is } \\
\text { deliberately excluded }\end{array}$ \\
\hline & & Exclusion of stakeholders from the process \\
\hline & \multirow{3}{*}{ Independence } & Management and facilitation of the process \\
\hline & & Equality of stakeholders in the process \\
\hline & & Stakeholders views and opinions are heard \\
\hline & \multirow{3}{*}{ Influence } & Stakeholders responses and proposals are respected \\
\hline & & $\begin{array}{l}\text { Stakeholders have the power to influence the process } \\
\text { and its outcomes }\end{array}$ \\
\hline & & Capacity building \\
\hline & Transparency & Transparency of the process \\
\hline \multirow{5}{*}{ Process criteria } & \multirow{3}{*}{ Accessibility } & Information resources \\
\hline & & Material resources \\
\hline & & Time resources \\
\hline & Cost-effectiveness & Financial resources \\
\hline & Task definition & Nature and scope of a participation process \\
\hline
\end{tabular}

A central element of effective collaboration is also transparency. The process should be transparent so that the stakeholders can see what is going on and how decisions are being made. Stakeholders should be informed, e.g., about what the purpose of their participation and involvement is, what they can influence, and who can participate and how. A genuine attempt to share information means that organizers actively ensure that all stakeholders are aware of, and understand, the relevant information [47].

It is clear that an effective decision-making process requires access to appropriate and relevant information, which means that land owners should have free access to this information to enable them to successfully fulfill their briefing. Accessibility includes: (a) information resources and access to them (summaries of the pertinent facts); (b) material resources (e.g., overhead projectors, whiteboards), and (c) time resources (stakeholders should have sufficient time to make a decision). Possible difficulties in a participatory process also revolve around the issues of finance. The participatory process should be cost-effective, which means that appropriate finances are available, and that the key concern for those organizing a participatory process is a value for money. Prior to conducting a participatory process, it is clearly sensible to take into account the potential costs of the methods, in both time and money, and to consider the extent to which they fulfill the objectives [34]. Each participatory process should clearly define the nature and scope of the participation tasks. It is important to ensure that there 
is as little confusion and dispute as possible regarding the scope of a participation process, its expected output, and the mechanisms of the procedure. All of these aspects should be clearly defined at the outset [35].

According to this conceptual framework, the 266 surveys and 17 interviews were analyzed with focus on the participatory process for the PUN (2015-2020).

\section{Materials and Methods}

The methodological approach in this analysis can be characterized as a theory-driven study of the latest PUN process in Slovenia. For insight into the formulation of process PUN 2015-2020, we reviewed and analyzed the project reports of the Operational Program for Managing Natura 2000 sites in Slovenia. The analysis provided us with information about the activities that have taken place, their order, and their duration. Furthermore, through the review of the reports, we obtained a list of the stakeholders, who participated in the process of formulating the PUN 2015-2020.

In order to analyze how stakeholders' involvement and participation have evolved in the process of formulation of PUN 2015-2020 in Slovenia, the methodological approach in the present study is based on a triangulation of methods-qualitative and quantitative. Therefore, in the first phase, in-depth semi-structured interviews with representatives of the key stakeholders' institutions or organizations that were responsible for, or involved in the formulation of, the PUN were carried out. In the second phase, a survey of all stakeholders involved in the formulation and decision-making of PUN 2015-2020 was conducted.

\subsection{Interviews with Stakeholders}

Detailed interviews were administrated to 17 stakeholders representing 11 institutions or organizations, which accounted for $11.7 \%$ of the total institutions that were involved in the formulation of the PUN (Table 2). When identifying and selecting stakeholders, a purposive sampling was used, where information-rich stakeholders are chosen, because they have particular features or characteristics which will enable detailed exploration and understanding of the central theme and puzzles which the research wish to study [50]. This approach aims to ensure that all key stakeholders are taken into account, and that some diversity is included.

Table 2. Stakeholders Involved in the Interview.

\begin{tabular}{cc}
\hline Name of Institution/Organization/Association & $\mathbf{N}^{\circ}$ Respondents \\
\hline Ministry of Environment and Spatial Planning & 3 \\
Institute of the Republic of Slovenia for Nature Conservation & 1 \\
Slovenia Forest Service & 3 \\
Institute for Water of the Republic of Slovenia & 1 \\
Triglav National Park & 2 \\
Farmland and Forest Fund of the Republic of Slovenia & 1 \\
University of Ljubljana-Biotechnical Faculty & 1 \\
Agricultural Institute of Slovenia & 1 \\
Centre for Cartography of Fauna and Flora & 1 \\
Chamber of Agriculture and Forestry of Slovenia & 2 \\
Fisheries Research Institute of Slovenia & 1 \\
\hline Total & 17 \\
\hline$N^{\circ}$-number.
\end{tabular}

The first version of the semi-structured interview was pre-tested in May 2015, and interviews conducted between December 2015 and January 2016.

The framework of the interview was prepared with the aim to analyze five main aspects of the participatory process: (1) the role of the institution and the personal role of the interviewee in the process of formulating the PUN (2015-2020); (2) the level of participation and stakeholders involvement; (3) the evaluation of participation in the process; (4) the transparency of the process and (5) 
the management and organization of the process. Table A1 in the Appendix A presents the distribution of interviewees according to the evaluation Sub-Criteria for an Effective Participatory Process.

All interviews were voice recorded and later transcribed. The length of interviews ranged between 20 and $35 \mathrm{~min}$, with an average of $22 \mathrm{~min}$. The data collected with interviews was analyzed through a content analysis using codes and their sub-codes (e.g., role of institution, participation, conflicts, agreement) with the support of MAXQDA 10 software (VERBI GmbH: Berlin, Germany).

\subsection{Survey of the Stakeholders}

In the first step of the research, a preliminary list of stakeholders involved in PUN was created based on list of participants in the workshops and reports of the LIFE ${ }^{+}$project. Eight hundred and fifteen stakeholders from 94 different institutions and organizations (i.e., ministry, public forest administration, NGOs, university and research institutions, private forest owners and farm associations) were identified as a study population. In the second phase, a sample size of 261 stakeholders was calculated with the help of Sample Size Calculator [51], (confidence level 95\%). In order to maximize the response rate and to reduce survey error, Dillman's Tailored Design Methods (TDM) [52] was adopted. Therefore, the questionnaire was sent by post to 767 identified stakeholders using the $1 \mathrm{KA}$ web survey program (https: / / www.1ka.si). The response rate was 34.8\%, with 266 filled questionnaires from representatives of 39 different institutions, which is $41.2 \%$ of all involved institutions.

Stakeholders were categorized into seven groups of interest: Governmental organizations (e.g., ministries), public administrations (e.g., SFS), local communities (e.g., municipalities), environmental NGOs, Chambers and Associations (e.g., CAFS, Association of Forest Owners), universities and research institutes (e.g., Biotechnical Faculty) and others (private companies). The majority of respondents involved in our survey were from public administration (42.9\%), followed by respondents from Chambers and Associations (21.1\%), governmental organizations (9.7\%), universities and research institutes (4.9\%), others (4.1\%), environmental NGOs (2.3\%) and local communities (0.7\%) (Table 3).

Table 3. Stakeholders Involved in the Survey.

\begin{tabular}{ccc}
\hline Group of Stakeholders & $\mathbf{N}^{\circ}$ Sample & $\mathbf{N}^{\circ}$ Respondents \\
\hline Governmental Organizations & $98(12.8 \%)$ & $26(9.7 \%)$ \\
\hline Public Administrations & $244(31.9 \%)$ & $114(42.9 \%)$ \\
\hline Local Communities & $25(3.2 \%)$ & $2(0.7 \%)$ \\
\hline Environmental NGOs & $19(2.5 \%)$ & $6(2.3 \%)$ \\
\hline Chambers and Associations & $298(38.9 \%)$ & $56(21.1 \%)$ \\
\hline Universities and Research Institutes & $42(5.4 \%)$ & $13(4.9 \%)$ \\
\hline Others & $41(5.3 \%)$ & $11(4.1 \%)$ \\
\hline Total & 767 & $\begin{array}{c}266 \text { (Because the survey was anonymous, 38 (14.3\%) } \\
\text { respondents choose not to reveal their institution.) }\end{array}$ \\
\hline
\end{tabular}

The questionnaire-comprising both open-ended and closed-ended questions-consisted of five sections seeking information on: (1) nature protection policies; (2) the participatory process and the relations between stakeholders; (3) the influence of stakeholders on the process; (4) conflicts and (5) the socio-demographic characteristics of stakeholders. In Sections 2 and 3, several questions were asked with the aim of gathering information on stakeholders' involvement and participation in PUN 2015-2020. The questions in the survey were developed based on the criteria for the evaluation of a participatory process [35].

For each of the indicators for the evaluation of the participatory process, the stakeholders were asked to evaluate their satisfaction on a five-point Likert scale (1-fully unsatisfied to 5-very satisfied). Based on these evaluations, average values were calculated for each indicator. The questionnaire was pre-tested in June 2016, and the survey data was collected in September and October 2016. 
Collected data was coded and inserted in MS Excel and processed in IBM's SPSS Statistics 21.0 software (International Business Machines Corporation: New York, United States of America).

In order to check the quality of the data and to detect errors, outliers, and missing values, all data was first checked with frequencies. In order to determine the normality of the data, normality tests (Kolmogorov-Smirnov and Shapiro-Wilk) were used [53]. In this case, data were not normally distributed; therefore, non-parametric tests were used [53]. As one of the objectives of this study was to present the differences among the stakeholders' evaluation of the participatory process according to their role (stakeholders from project partner's institution and other stakeholders) in the implementation process, a comparison was made between those stakeholders' groups. Hence, in order to determine the differences between these two groups, the non-parametric Mann-Whitney U test was used. The differences between groups were statistically tested using the Mann-Whitney $\mathrm{U}$ test $(p \leq 0.005)$. The statistical results of Mann-Whitney $\mathrm{U}$ test are presented in Table A2 in Appendix A.

\section{Results}

\subsection{Stakeholders' Evaluation of the Acceptance Criteria}

\subsubsection{Representativeness of the Participatory Process}

The participatory process applied in the formulation of PUN 2015-2020 in Slovenia involved different stakeholders from the early beginning of the process. First, the project coordinator (MESP), together with project partners, made a detailed analysis of the stakeholders, based on sector involvement and type of institution, and prepared influence/interest matrix for potential stakeholders' prioritization and a precise plan of their involvement in different stages of the process: "The selection criterion for stakeholders to participate in the process was that they are institutions with an interest and competency in the planning and implementation of nature protection policies and measures" [MESP 1]. Consequently, the formulation of PUN 2015-2020 brought together a broad range of stakeholders from different sectors, which is confirmed by the results of the interviews, in which $70.7 \%$ of interviewed stakeholders agreed with the statement that the process was representative, $17.6 \%$ were indifferent, and $11.7 \%$ disagreed. On the other hand, the results from the survey also confirmed these findings, where the indicators for the evaluation of participatory process, i.e., "A broad range of stakeholders involved", and "Relevance of the involved stakeholders", were evaluated respectively as satisfied (average value $3.24 \pm 0.983$ and $3.18 \pm 0.937$ ). Moreover, the Mann-Whitney $U$ test did not show statistically significant differences between stakeholders from the project's partner institutions and other stakeholders for both indicators.

On the other hand, the stakeholders also felt that some groups were excluded from the process (landowners and people living in the Natura 2000 areas i.e., general public etc.): "Landowners under Natura 2000, especially those who are economically dependent on agriculture and forestry were not directly involved" [CAFS 2].

\subsubsection{Independence of the Participatory Process}

The management and facilitation of the PUN 2015-2020 was in the hands of project coordinator and partners. The draft version of PUN 2015-2020 was discussed in 6 workshops with a wider group of key stakeholders (219 representatives). The workshops were prepared separately for different sectors (forestry, agricultural, fisheries, and water) and local communities (workshops for the eastern and western part of Slovenia). The participation was based on consultation, collection of propositions/comments, and the elaboration of a final draft. The final draft was sent for intergovernmental consultation following the adoption of the PUN 2015-2020. After the adoption of PUN 2015-2020, 8 workshops were held for project partners and other target audiences (623 stakeholders) to spread information about PUN 2015-2020. 
The results of the survey showed that the indicator "Workshop organization" was evaluated on average as $3.80 \pm 0.848$, and "Management and facilitation of the process" as $3.71 \pm 0.831$, which means that stakeholders were satisfied with the organization of the participatory process. The Mann-Whitney U test did not show statistically-significant differences between stakeholders from project partner's institutions and other stakeholders for both indicators. The survey results are also supported by the results of interviews, where $82.3 \%$ of interviewed stakeholders agreed with the statement that the process was independent, $11.8 \%$ were indifferent, and 5.9\% disagreed, which is seen in the respondents' opinions: "The workshops were conducted according to established rules, useful and successful. We were absolutely satisfied with the workshops, because there was always the possibility to express our opinion" [CAFS 1]; SFS 1: "In the draft process, when we coordinated with the content, we received a record where it was clear what was changed. We updated the content regularly on the screen during the workshops and got a record that we could put comments on and comments were taken into account".

On the other hand, a few stakeholders were not satisfied with management and facilitation of the process and fairness of workshops and feedback from organizer of process: "We were invited to the workshop for presentation the draft, and at that time we were not given the full picture of the content creation process, how the process is proceeding, and whether we are expected to have any other proposal, cooperation" [representative of RDA Green Karst 1].

The role of facilitator is important for an effective participatory process. The facilitators were nominated by project partners who identified internal persons from IRSNC. The stakeholders' highlighted that the role of facilitator was crucial in the participatory process for the formulation of PUN 2015-2020. Particularly, the facilitator encourages trusting relationships and equality between the participants, so that mostly all stakeholders' views were heard and respected. The results of the survey evaluated the indicator for the evaluation of the participatory process "Stakeholders views and opinions are heard" on average as $3.43 \pm 1.016$, and "Equality of stakeholders in the process" as $3.35 \pm 1.021$, which means that stakeholders were fairly satisfied. The Mann-Whitney U test did not show statistically significant differences between stakeholders from project partner's institutions and other stakeholders.

The survey results are also supported by the interviews, where respondents stated: "I think that everybody has the possibility to express their opinion, if they have an interest" [IFRS 1].

\subsubsection{Influence in the Participatory Process}

The stakeholders who were present at the workshops contributed to the co-creation of PUN 2015-2020 through their active participation, as highlighted also by a respondent: "The stakeholders' contribution to the PUN was great; they made it more practical, so it has more chance for implementation. It can be said that, from the draft to the proposal, a great improvement has been made" [IRSNC 1] and "At workshops where we prepared the draft, we self-coordinated about the substance and then got feedback from the IRSNC, so we simultaneously repaired the draft and presented it on big screen. Most of the notes were included in the draft later on" [SFS 1].

The level of participation is strictly linked to the power of stakeholders to influence the process and outcomes in the participatory process. Yet, the stakeholders' experiences of having an actual influence on the formulation process varied. Stakeholders from partner institutions felt that their interests and proposals were adequately represented in the final version of PUN, which is also confirmed by the results of the interviews, where $70.7 \%$ of interviewed stakeholders agreed with the statement that they had influence on the process, $17.6 \%$ were indifferent, and $11.7 \%$ disagreed. The results from the survey also confirmed this finding, where stakeholders were least satisfied with the indicator "Stakeholders' response and proposals were respected" (average value $2.99 \pm 0.976$ ) and "Power of stakeholders to influence the process and its outcomes" (average value $2.82 \pm 0.996)$. Moreover, the Mann-Whitney U test did not show statistically significant differences between stakeholders from project partner's 
institutions and other stakeholders. The results also show a slightly higher influence of the institutions than the influence of individuals, as the average estimate of the influence of institutions was 2.97.

However, not all interviews supported the results of the survey. Some of stakeholders felt that they had little, if any, influence on the final version of PUN 2015-2020. According to the representative of NGOs, they had an impact on the draft version of PUN, but not all their proposals were considered at the end. "The ultimate decision-making power was possessed by IRSNC, who took the final decision concerning the draft and some of our proposals were ignored. We also made comments on the public meeting about some measures, but we were not heard and did not get an answer" [Bird Life NGO 1].

Also, partner institutions noticed that other stakeholders had limited influence, arguing that: "Some content stayed uncoordinated. We were approaching the finalized management program through the entire process, but we were not completely harmonized with other stakeholders about some of the content" [SFS 1] or "IRSNC did not take comments into account when they were contrary to the opinions of Bird Life NGO" [SFS 3]. However, some representatives from partner institutions claimed that they had limited power to influence the process and its outcome. For example, the representative of IWRS 1: "We had to accept some of the objectives and measures and try to understand them as best as possible" and representative of SFS 3: "In the reconciliation of the PUN, we could only make our comments by problematizing the issue of the positive opinion of the institution in intergovernmental consultation".

Capacity building is clearly the most concrete outcome of the formulation of the PUN 2015-2020 process that has taken place during the period 2012-2015. It was a valuable forum to receive and exchange information, and to some extent, to build shared understanding of nature conservation problems. In addition, the results of the survey show that "Capacity building" was evaluated with an average value $3.04 \pm 0.842$. The Mann-Whitney $U$ test did not show statistically significant differences between stakeholders from project partner's institutions and other stakeholders.

The interviews supported the results of survey, which is seen in a statement of the representative of IWRS 1: "I think that the team from the ministry was great, probably could not be better. I know, because I participated in other projects with other ministries where we had problems. Here everything went smoothly. When we presented our program on workshops I always had a feeling of security and I believed in the program". A further statement which supports the results is from a representative of MESP 1: "There is an important benefit of the partnership, because each of the five partners is a responsible authority in their field of work, and project results require joint understanding and joint solutions. As an example, analyses were prepared e.g., for Natura 2000 on agricultural land by the IRSNC, which has knowledge and experience on the nature conservation aspect of achieving objectives and the measures implemented, and by CAFS, which has knowledge and experience on the agricultural aspect of implemented measures, and stakeholders experience. Without both institutions involved there would be only one analyzed perspective. The same goes for forests and waters and fisheries".

Capacity building has influenced the sharing of information as representative of CAFS 1 explained: "For our needs within the framework of some project activities, we needed data that we did not have. The MESP has easily provided us with this information" and IWRS 1: "Any information or data we needed concerning the project from any project partner was not a problem to get it".

\subsubsection{Transparency of the Participatory Process}

The transparency of the participatory process was evaluated generally as satisfactory, as $45.6 \%$ of the respondents of the survey answered that the process was transparent or very transparent (average value of transparency: $3.26 \pm 0.917$ ). The results were also supported by the results of the interviews, where $76.6 \%$ of interviewed stakeholders agreed with the level of transparency of the process, $11.7 \%$ were indifferent, and 11.7\% disagreed. Among the answers of the interviewees: "For me, the PUN process was transparent, because I was part of the team and got an inside look on how the system works" [SFS 1] and "Yes, I believe that the process was transparent, because the starting point was adjusted to ensure the transparency of the process and it worked" [CAFS 1]. 
Those respondents from the survey and interviews who were not satisfied with the transparency of the participatory process $(21.3 \%)$ mentioned that the main reason for inadequate transparency was the lack of feedback on their comments at the workshops, the lack of information on the content editing (what can be changed and what cannot), which phase the process of creating the PUN is in, the state of future cooperation methods, who has already been involved in the process of creating the PUN, and who else will be.

This is also evident from the survey answers and statements of interviewed stakeholders: "There was a selective invitation for participation at the process and the workshops were not recorded ... participants did not receive any feedback, the final version of PUN was changed beyond the knowledge of the participants" [SFS 1], "There was a lack of stakeholders' awareness and their insufficient involvement. Those of us, who were involved, did not receive any information about the process itself" [NIB 1], and "The process is not transparent, because there is no feedback or information on what stage the PUN is in" [SFS 3]. The final version of the PUN 2015-2020 was adopted by MESP and IRSNC, and did not take all the recommendations of stakeholders into consideration, as pointed out by a respondent in the survey: "The final decisions were not drawn up at the workshops, but later, after the reconciliations between the ministries, where the other stakeholders were no longer included. Final decisions should be taken with the consensus of all stakeholders" [Biotechnical Faculty 1], and "There were no clear instructions, participants were selectively invited, workshops did not keep a record, there was no feedback, the final document was changed without the participants' knowledge, different information was provided at the time of preparation on the meaning and usability of PUN, as it turned out later upon confirmation" [NGO 1].

Moreover, the Mann-Whitney $U$ test showed statistically significant differences between stakeholders from project partner's institutions and other stakeholders $(U=1260.500, z=-3.018$, $p=0.03$ ). Stakeholders from project partner's institutions evaluated sub-criteria with an average value of 3.60, while other stakeholders evaluated it with an average value 2.80 , which means that stakeholders from project partner's institutions were more satisfied with the transparency of the process than other stakeholders.

\subsection{Stakeholders Evaluation of the Process Criteria}

\subsubsection{Accessibility of the Participatory Process}

Access and flow of information in the process of formulating the PUN 2015-2020 was satisfactory, as different means of communication were used, depending on which stakeholders they wanted to reach i.e., mass media, project website, formal invitations on workshops. The main source of information was the project's website, where all of the project's steps were published.

Stakeholders were generally satisfied with the accessibility of the participatory process, which is confirmed by the results of the interviews, where $82.4 \%$ of interviewed stakeholders agreed with the accessibility of the information in the process, $5.9 \%$ were indifferent, and $11.7 \%$ disagreed.

Stakeholders were satisfied with the material resources as the answers of the survey, where the indicator "Intelligibility of the material and information" was evaluated with an average value of $3.47 \pm 0.861$, and indicator "Notification of certain activities" with $3.11 \pm 0.951$. The stakeholders' satisfaction with material resources was pointed out by the interviewed representative CAFS 1: "We got access to the data that the ministry had for our needs, so we cooperated well". Respondents also evaluated the indicator "Free access to all information" as satisfactory (average value $3.41 \pm 0.881$ ).

Stakeholders had sufficient time for reflection, to make a decision and to express their opinions, comments and thoughts about the content of PUN, as stated by representative: " . . there was almost one year of these public announcements, so whoever had an interest had the opportunity to suggest or comments the PUN" [IFRS 1]. 


\subsubsection{Cost-Effectiveness}

Analysis of the costs of PUN is crucial in order to assess cost-effectiveness. The project's budget was 1,706,914.00€, where the financial contribution of European Union was 50.0\% [54]. The largest share of the expenses represents personnel costs as 62 staff worked on the project altogether. The largest expenses in this budget line represents the implementation of the workshop for preparing the first draft, followed by project management and analysis of measures implemented and objectives achieved from PUN 2007-2013. The planned financial resources were sufficient through internal redeployment of resources, according to representative IRSNC 1: "The planned financial resources for workshops for the first draft were underestimated at the time of application, but we provided enough money with internal redeployment of funds".

Stakeholders from project partner's institutions who were directly involved in the project were satisfied with the cost-effectiveness, which is confirmed by the results of the interviews, where $47.1 \%$ of interviewed stakeholders agreed with the cost-effectiveness of the project, and $52.9 \%$ of stakeholders are indifferent because they were not directly involved in the project and could not respond to the question.

\subsubsection{Task Definition}

The nature and scope of the participation task were defined between the partners of the PUN 2015-2020 project in a document called "Process and Communication Plan". The document represents a detailed plan of the implementation of this project, defining the project phases, actions of each phase, its activities, and the tasks of each partner. Additionally, the time schedule and correlations between tasks were defined as well.

The stakeholders who were involved as partners knew from the very beginning what their role and tasks were. "I think that, even within the institution, we have explained how things are going, so everyone knew where to get the information and to whom to send comments ... so the tasks were clearly defined" [SFS 1].

However, not all stakeholders knew that; this was especially the case among stakeholders who were included only in the phase of the draft presentation. This is seen from the survey answer of the of rural development agency Green Karst 1: "We were invited to the workshop where the draft was presented and at that point, we were not given the whole picture of the creation process. We also did not receive any feedback after the workshop regarding which proposal was taken into account, how the process was proceeding, and whether we are expected to offer any other proposals or cooperation".

Additionally, $47.1 \%$ of interviewed stakeholders agreed with the task definition and the document "Process and Communication Plan". The rest of the stakeholders were indifferent because they were not involved in the project ( $\operatorname{LIFE}^{+}$), so they were not familiar with the document.

\section{Discussion}

The success of the nature conservation policy depends on stakeholders' co-operation and participation [19]. The analysis of stakeholders' involvement in the decision-making process of PUN 2015-2020 in Slovenia is a prerequisite for successful participation in order to highlight a wide range of interests and point-of-views between different groups of stakeholders.

This study shows that the set of acceptance and process criteria and indicators can be used as a basis for the evaluation of the participatory process in nature conservation and forest policy. The information retrieved from the survey and interviews of the stakeholders indicates that the participatory process was designed by considering the representativeness, independence, influence, transparency, resource accessibility, cost-effectiveness, and task definition criteria. In some EU countries, the participatory process was organized in the same way [31,32,34]. This shows a positive trend from a command and control approach towards a participatory approach not only in PUN 2015-2020, but also in other EU countries $[1,55,56]$, which means that various groups of stakeholders 
could influence policy outcomes in several ways [8]. Overall, however, not all of the requisite conditions for successful participation were created by the evaluated participatory process. Studies $[31,32,34,57]$ show that some conditions for successful participation were not achieved. This indicates the possibility for an improved, novel and innovative approach that leads to multi-level governance and a better participatory process.

For example, with regard to the stakeholders' involvement in the process, the main limit was that some groups of stakeholders felt excluded from the process or were only included in the final phase (i.e., landowners and general public), or that stakeholders did not perceive that other stakeholder groups were also involved in process of the formulation of PUN 2015-2020. A reason for that could be the organization of separate workshops for different sectors, in which only a part of the stakeholders were present, or the fact that only the interests of privileged stakeholder groups were included in the decision-making process, while other marginalized stakeholders were only informed about the results of the process in the final phase. During the consultation meetings on intergovernmental consultation, MAFF did not give his consent to MESP for the adoption of PUN 2015-2020, until a consensus between SFS and IRSNC about the measures related to forestry and nature conservation under Natura 2000 was reached; e.g., one of the topics was the amount of dead wood that should stay in the forest. The aim of the meeting was to reach a consensus on an expert level. Therefore, more participation of marginalized stakeholder groups at the early and final stages is needed, and should be based on consensus decision making and involvement which would improve the participation process.

Moreover, to improve the management and facilitation of the process, it is important to know the role that stakeholders play in the process. Therefore, more attention should be given by project partners to the presentation of the Process and Communication Plan. In addition, the facilitators of the PUN 2015-2020 were very professional and capable of facilitating an open-discussion, and equally, of supporting stakeholders in expressing their opinions, needs, and interests. However, the choice of the facilitator should be reconsidered and assigned to an external person who is not affected by the topic of discussion in order to improve the independence of the participatory process [31,35]. The role of facilitator is essential to ensure equality among stakeholders in the process [31,58].

The adopted participatory approach in PUN 2015-2020 was less centralized than the previous one, but it was still a top-down oriented approach with a switch from a more information-based communication with stakeholders, as in the previous process, to a consultation with key stakeholders. This finding is in accordance with studies evidencing that the initial top-down approach practiced in most countries was changed to more socially inclusive and participatory bottom-up approaches [34,59-61]. Still, stakeholders felt that all their responses and proposals were not taken into consideration. To improve the perceived influence of stakeholders, project partners need to connect participation with co-responsibility [15].

The level of participation is strictly linked to the power of stakeholders to influence the final decision in the participatory process [62]. According to the results, stakeholders had conflicting opinions on their real ability to influence the policy process and the final decisions. This is not surprising, as project partners were the organizers of the process, the actors who selected the stakeholders, the participants in process, and facilitators at the same time. Accordingly, the stakeholders who were involved in the process participated with different levels of involvement and power to influence the process. This finding confirms that using participation techniques does not guarantee that the stakeholders will feel empowered, but they are very useful tools to get the stakeholders' opinions [57]. According to the results, the ultimate decision-making power was held by the MESP and IRSNC who made the final decision. This is not problematic per se, according to [63] (p. 329): "As with all public policy issues, the government should have the last word" (p. 329). Other studies have shown similar problems regarding the influence and the power of stakeholders that emerged as a consequence of the adopted top-down approach $[61,64,65]$. It seems that, in future participatory processes, it would be beneficial if project partners would conduct another round of workshops to consult a broad range of stakeholders. These workshops can be considered to incorporate the stakeholders' ideas and comments. 
This would improve the transparency of the process and obtain new opportunities for stakeholders to exert their influence.

In general, the transparency of the decision-making process in PUN 2015-2020 was guaranteed, but $21.3 \%$ of stakeholders were still not entirely satisfied with it. That was also confirmed by the Mann-Whitney $U$ test. The project partners were more satisfied with the transparency of the participatory process than other stakeholders. Therefore, a more transparent process would represent a significant asset, including adequate information for included stakeholders and the land owners (via website), proper planning and preparation of the consultation process, respecting process results, and an improved communication gap between policymakers and other relevant stakeholders, which means keeping them constantly informed about the process and any further steps. With regard to the stakeholders involved in the process, the limit was the low level of participation of land owners. In order to increase the future legitimacy and transparency of the PUN formulation process, land owners should be involved more actively in the decision-making. This was similarly deduced in the formulation of the National Forest Program in the Czech Republic [31]. In this respect, a good example is represented by the Austrian Forest Forum, where land owners had the chance to participate in the dialogue process via an Internet platform or through written statements. Moreover, in the Austrian Forest Forum, land owners were kept informed through a Forest Dialogue Newsletter [66].

The important resources in a participatory process are information, and material and time resources. The availability of these resources is progressing in PUN, but it needs more capacity and resources in terms of better communication with stakeholder groups. According to the organizer of the process, financial resources were sufficient. Restrictions on financial resources are liable to have an impact on the quality of the participation process. It is essential to ensure that appropriate finances are available.

Concerning the task definition criteria, tasks between stakeholders who were involved as project partners were very precisely defined. However, stakeholders from other institutions or stakeholders from the same institutions who were involved in a later phase of the process (presentation of draft) did not know that. To improve those criteria, what the purpose of stakeholders' participation is/their tasks and what is expected from them should be clearly stated at the beginning of each workshop.

When interpreting the results of this study, one should note that the approach has some limitations. The analysis only considers the opinions regarding the evaluation of the participatory process of formulation of PUN 2015-2020 of stakeholders who participated in the study. Relying on the answers of respondents (266), this study does not reveal the opinions of the silent majority on the evaluation of the participatory process of the formulation of PUN 2015-2020, nor how they will act in the future. Moreover, the present results could be biased, because only representatives of private landowners were involved in the process and consequently in our study, but they are especially relevant for the management of Natura 2000. Their absence from the process was recognized by the respondents, and is indicated in the results section. The real reason for their absence is unknown. The most likely reason could be a lack of interest in participation in the process; less likely reasons could also be a boycott, which can result in serious opposition in the future or in political radicalization. Those two reasons are less likely, because representatives of the Association of Forest Owners were invited to round tables (public meetings) where they could have given input on a draft version of PUN, but they did not attend. In addition, they were present in last phase of workshops when the PUN 2015-2020 was already adopted by the government. The reason for the lack interest could be a lack of knowledge on how to argument their opinions in order to influence the draft version, or because the aim of PUN 2015-2020 was not changing the borders but to establish measures to achieve conservation objectives of species and Natura 2000. However, the number of respondents in the survey was large enough to present the full picture of the process. 


\section{Conclusions}

There is increasing contention that public participation in policy-making is necessary to reflect and acknowledge democratic ideals and to enhance trust in regulators and transparency in regulatory systems [35]. Consequently, the participation of stakeholders in nature conservation policies, such as PUN, and especially in the management of protected areas, such as Nature 2000, has gained importance in the last decades.

The detailed analysis described in the previous sections gives us a general overview of the participatory process and stakeholders' involvement in the process of formulation of PUN 2015-2020 in Slovenia. The process was assessed based on evaluation criteria for an effective participatory process, taking into account the acceptance criteria (representatives, independence, influence and transparency) and process criteria (accessibility, cost-effectiveness and task definition). It is evident from research that these criteria do not function independently, and it is therefore important to pay attention to all of them. For example, a transparency criterion relates to influence criteria and vice versa.

Therefore, evaluating the participatory processes is essential to increase the quality of future processes. Such an evaluation can be useful for the organizations responsible for planning and management, as well as stakeholders and policy makers. In order to obtain good results, the managers need to have guidelines to help them in designing and carrying out a successful participatory planning process.

While a number of different participation techniques have been developed, their relative usefulness is difficult to ascertain, because there are either no systematic comparisons between them or they are rare. Our evaluation was done ex post, based on quantitative and qualitative analysis, and carried out by a researcher related to the participatory processes as an observer. We are aware of the fact that the chosen criteria can have multiple meanings, and that stakeholders might define the criteria in a different way.

The results of this study can be applied for stakeholder involvement in the participatory processes in other natural resource management situations or similar processes of policy formulation activities. The usefulness of this research is to improve participatory processes in future PUN and other nature conservation and forest-related programs.

Finally, every process of formulating the policy is different, and the participation techniques used should be considered on a case by case basis. However, lessons can be learned from this case and used to develop participation techniques and more customer-oriented planning.

Author Contributions: The authors have contributed to this study in equal parts. The results and article are part of emerging Ph.D. at Biotechnical Faculty, University of Ljubljana of T.L. and his supervisor Š.P.M., with the title: "The characteristics of the Social Networks and Participation of Stakeholders in the Management of Natura 2000 Sites".

Funding: This research was funded by Pahernik foundation. Authors wish to thank to the foundation for supporting the publishing of results.

Acknowledgments: First: we wish to thank to all the interviewees and respondents who took part in this research and made it possible by sharing their experiences. We also want to thank to the anonymous reviewers for their contributions and special issue guest editor of section "Forest Economics and Human Dimensions" Alessandro Paletto. Finally we would like to thank to Saša Petrovič and Ana Marija Laktić for proofreading.

Conflicts of Interest: The authors declare no conflict of interest. Both authors declare that they are not NGO members and that they do not own forest land. 


\section{Appendix A}

Table A1. Distribution of Interviewees According to the Evaluation Sub-Criteria for an Effective Participatory Process.

\begin{tabular}{|c|c|c|c|}
\hline Sub-Criteria & Agreed & Undefined & Disagreed \\
\hline Representativeness & $\begin{array}{l}\text { SFS } 1 \text { MESP } 1 \text {, MESP } 2, \text { MESP } 3 \text {, } \\
\text { CAFS } 1 \text {, FRIS } 1 \text {, IRSNC } 1 \text {, IWRS } 1 \text {, } \\
\text { TNP } 1 \text {, AIS 1, BF 1, FFFRS } 1\end{array}$ & CCFF 1 , SFS 3 , TNP 2 & CAFS 2 SFS 2 \\
\hline Independence & $\begin{array}{l}\text { MESP 1, MESP 2, MESP 3, IRSNC 1, } \\
\text { SFS 1, SFS 3, SFS 2, IWRS 1, AIS 1, } \\
\text { BF 1, CCFF 1, CAFS 1, FRIS 1, FFFRS } 1\end{array}$ & TNP 2, CAFS 2 & TNP 1 \\
\hline Influence & $\begin{array}{l}\text { MESP } 1 \text {, MESP 2, MESP 3, IRSNC 1, } \\
\text { SFS 1, SFS 2, AIS 1, BF 1, CCFF 1, } \\
\text { CAFS 1, FRIS 1, FFFRS } 1\end{array}$ & & $\begin{array}{l}\text { SFS 3, IWRS 1, TNP 1, } \\
\text { TNP 2, CAFS } 2\end{array}$ \\
\hline Transparency & $\begin{array}{l}\text { MESP } 1 \text {, MESP 2, MESP 3, IRSNC 1, } \\
\text { SFS 1, SFS 2, IWRS 1, TNP 1, TNP 2, } \\
\text { AIS 1, CAFS 1, FRIS 1, FFFRS } 1\end{array}$ & CCFF 1 , CAFS 2 & SFS 3, BF 1 \\
\hline Accessibility & $\begin{array}{l}\text { MESP 1, MESP 2, MESP 3, IRSNC 1, } \\
\text { SFS 1, SFS 2, IWRS 1, TNP 2, AIS 1, } \\
\text { BF 1, CAFS 1, CAFS 2, FRIS 1, FFFRS } 1\end{array}$ & CCFF 1 & SFS 3, TNP 1 \\
\hline Cost-effectiveness & $\begin{array}{l}\text { MESP } 1 \text {, MESP 2, MESP 3, IRSNC } 1 \text {, } \\
\text { SFS } 1 \text {, IWRS } 1 \text {, CAFS 1, FRIS } 1\end{array}$ & $\begin{array}{c}\text { SFS 3, SFS 2, TNP 1, CCFF } 1 \text {, TNP } \\
2 \text {, AIS } 1 \text {, BF 1, CAFS } 2 \text {, FFFRS } 1\end{array}$ & \\
\hline Task definition & $\begin{array}{l}\text { MESP 1, MESP 2, MESP 3, IRSNC 1, } \\
\text { SFS 1, IWRS 1, CAFS 1, FRIS } 1\end{array}$ & $\begin{array}{l}\text { SFS 3, SFS 2, TNP 1, TNP 2, AIS 1, } \\
\text { BF 1, CCFF 1, CAFS 2, FFFRS } 1\end{array}$ & \\
\hline
\end{tabular}

Table A2. Statistic results of Indicators for an Effective Participatory process.

\begin{tabular}{cccccc}
\hline Indicators & Mann-Whitney $U$ & $Z$ & $p$ & Mean & Std. Deviation \\
\hline Management and facilitation of the process & 1926.500 & -0.586 & 0.558 & 3.71 & 0.831 \\
\hline Workshop organization & 2036.00 & -0.165 & 0.869 & 3.80 & 0.848 \\
\hline A broad range of stakeholder involved & 1728.500 & -0.638 & 0.524 & 3.24 & 0.983 \\
\hline Relevance of the involved stakeholders & 1889.000 & -0.383 & 0.701 & 3.18 & 0.937 \\
\hline Access to information & 1887.500 & -0.869 & 0.385 & 3.41 & 0.881 \\
\hline Intelligibility of the material and information & 2122.000 & -0.299 & 0.765 & 3.47 & 0.861 \\
\hline Notifications of certain activities & 1931.500 & -0.904 & 0.366 & 3.11 & 0.951 \\
\hline Stakeholders views are heard and respected & 1851.500 & -0.819 & 0.413 & 3.43 & 1.016 \\
\hline $\begin{array}{c}\text { Stakeholders responses and proposals } \\
\text { are respected }\end{array}$ & 1732.000 & -1.043 & 0.297 & 2.99 & 0.976 \\
\hline $\begin{array}{c}\text { Power of stakeholders to influence process } \\
\text { and its outcomes }\end{array}$ & 1641.000 & -1.465 & 0.143 & 2.82 & 0.996 \\
\hline $\begin{array}{c}\text { Capacity building } \\
\text { Transparency }\end{array}$ & 1391.000 & -0.375 & 0.708 & 3.04 & 0.842 \\
\hline
\end{tabular}

\section{References}

1. Keulartz, J. European nature conservation and restoration policy-Problems and perspectives. Restor. Ecol. 2009, 17, 446-450. [CrossRef]

2. Jones-Walters, L.; Çil, A. Biodiversity and stakeholder participation. J. Nat. Conserv. 2011, 19, 327-329. [CrossRef]

3. Weber, N.; Christophersen, T. The influence of non-governmental organisations on the creation of Natura 2000 during the European Policy process. For. Policy Econ. 2002, 4, 1-12. [CrossRef]

4. Kati, V.; Hovardas, T.; Dieterich, M.; Ibisch, P.L.; Mihok, B.; Selva, N. The challenge of implementing the European network of protected areas Natura 2000. Conserv. Biol. 2015, 29, 260-270. [CrossRef] [PubMed] 
5. Rauschmayer, F.; Van den Hove, S.; Koetz, T. Participation in EU biodiversity governance: How far beyond rhetoric? Environ. Plan. Gov. Policy 2009, 27, 42-58. [CrossRef]

6. Beunen, R.; De Vries, J.R. The Governance of Natura 2000 Sites: The Importance of Initial Choices in the Organisation of Planning Processes. J. Environ. Plan. Manag. 2011, 54, 1041-1059. [CrossRef]

7. Šobot, A.; Lukšič, A. The Impact of Europeanisation on the Nature Protection System of Croatia: Example of the Establishment of Multi-Level Governance System of Protected Areas NATURA 2000. Socijalna Ekologija Časopis za Ekološku Misao i Sociologijska Istraživanja Okoline 2017, 25, 235-270. [CrossRef]

8. Ferranti, F.; Beunen, R.; Speranza, M. Natura 2000 network: A comparison of the Italian and Dutch implementation experiences. J. Environ. Policy Plan. 2010, 12, 293-314. [CrossRef]

9. Cent, J.; Mertens, C.; Niedziałkowski, K. Roles and Impacts of Non Governmental Organizations in Natura 2000 Implementation in Hungary and Poland. Environ. Conserv. 2013, 40, 119-128. [CrossRef]

10. Stringer, L.C.; Paavola, J. Participation in environmental conservation and protected area management in Romania: A review of three case studies. Environ. Conserv. 2013, 40, 138-146. [CrossRef]

11. Borrass, L.; Sotirov, M.; Winkel, G. Policy change and Europeanization: Implementing the European Union's Habitats Directive in Germany and the United Kingdom. Environ. Politics 2015, 24, 788-809. [CrossRef]

12. Winkel, G.; Blondet, M.; Borrass, L.; Frei, T.; Geitzenauer, M.; Gruppe, A.; Winter, S. The implementation of Natura 2000 in Forests: A trans-and interdisciplinary assessment of challenges and choices. Environ. Sci. Policy 2015, 52, 23-32. [CrossRef]

13. Van Apeldoorn, R.C.; Kruk, R.W.; Bouwma, I.M.; Ferranti, F.; De Blust, G.; Sier, A.R.J. Information and Communication on the Designation and Management of Natura 2000 Sites; The Designation in 27 EU Member States; Main Report 1; EC Publications: Brussel, Belgium, 2009.

14. Sarvašová, Z.; Šálka, J.; Dobšinská, Z. Mechanism of cross-sectoral coordination between nature protection and forestry in the Natura 2000 formulation process in Slovakia. J. Environ. Manag. 2013, 127, 65-72. [CrossRef] [PubMed]

15. Gil, A.; Calado, H.; Cost, L.T.; Bentz, J.; Fonseca, C.; Lobos, A.; Vergilio, M.; Benedicto, J. A Methodological Proposal for the Development of Natura 2000 Sites Management Plans. J. Coast. Res. 2011, 64, 1326-1330.

16. Margules, C.; Sarkar, S. Systematic Conservation Planning; Cambridge University Press: Cambridge, UK, 2007.

17. Weiss, G.; Sotirov, M.; Sarvašova, Z. Implementation of Natura 2000 in forests. In European Forest Institute-What Scienec Can Tell Us; Sotirov, M., Ed.; European Forst Institute: Joensuu, Finland, 2017; pp. 39-58. Available online: http://www2.efi.int/files/attachments/publications/wsctu7_2017.pdf (accessed on 25 September 2018).

18. Blicharska, M.; Orlikowska, E.H.; Roberge, J.M.; Grodzinska-Jurczak, M. Contribution of social science to large scale biodiversity conservation: A review of research about the Natura 2000 network. Biol. Conserv. 2016, 199, 110-122. [CrossRef]

19. Alphandéry, P.; Fortier, A. Can a territorial policy be based on science alone? The system for creating the Natura 2000 Network in France. Sociol. Rurals 2001, 41, 311-328. [CrossRef]

20. Hiedanpää, J. European-wide conservation versus local well-being: The reception of the Natura 2000 Reserve Network in Karvia, SW-Finland. Landsc. Urban Plan. 2002, 61, 113-123. [CrossRef]

21. Milligan, J.; O'Riordan, T.; Nicholson-Cole, S.A.; Watkinson, A.R. Nature conservation for future sustainable shorelines: Lessons from seeking to involve the public. Land Use Policy 2009, 26, 203-213. [CrossRef]

22. Blondet, M.; Koning, J.; Borrass, L.; Ferranti, F.; Geitzenauer, M.; Weiss, G.; Turnhout, E.; Winkel, G. Participation in the implementation of Natura 2000: A comparative study of six EU member states. Land Use Policy 2017, 66, 346-355. [CrossRef]

23. Reed, M.S. Stakeholder participation for environmental management: A literature review. Biol. Conserv. 2008, 141, 2417-2431. [CrossRef]

24. Saarikoski, H.; Tikkanen, J.; Leskinen, L.A. Public participation in practice-Assessing public participation in the preparation of regional forest programs in Northern Finland. For. Policy Econ. 2010, 12, 349-356. [CrossRef]

25. Ferlin, F.; Golob, A.; Habič, Š. Some principles for successful forest conservation management and forestry experiences in establishing the Natura 2000 network. In Legal Aspects of European Forest Sustainable Development, Proceedings of the 7th International Symposium, Zlatibor Mountain, Serbia, 11-15 May 2005; Schmithüsen, F., Herbst, P., Nonic, D., Jovic, D., Stanisic, M., Eds.; ETH Zürich: Zürich, Switzerland, 2005; pp. 1-11. 
26. Commission Staff Working Document. The EU Environmental Implementation Review Country Report-SLOVENIA. 2017. Available online: http:/ / ec.europa.eu/environment/eir/pdf/report_si_en.pdf (accessed on 25 September 2018).

27. Petkovšek, M. Slovenian Natura 2000 Network in Numbers; Varstvo Narave: Ljubljana, Slovenia, 2017; Volume 30, pp. 99-126.

28. Pezdevšek Malovrh, Š.; Leban, V.; Krč, J.; Zadnik Stirn, L. Slovenia: Country Report; COOL_Competing Uses of Forest Land: Ljubljana, Slovenia, 2012.

29. Medved, M.; Matijašić, D.; Pisek, R. Private property conditions of Slovenian forests in 2010. In Small scale forestry in a Changing World. Opportunities and challenges and the Role of extension and technology transfer. In Proceedings of the IUFRO Conference, Bled, Slovenia, 22-23 December 2010.

30. Pezdevšek Malovrh, Š. Influence of Institutions and Forms of Cooperation of Private Forest Owners on Private Forest Management. Ph.D. Thesis, Biotechnical Faculty, Department of Forestry and Renewable Forest Resources, Ljubljana, Slovenia, 2010.

31. Balest, J.; Hrib, M.; Dobšinská, Z.; Paletto, A. The formulation of the National Forest Programme in the Czech Republic: A qualitative survey. For. Policy Econ. 2018, 89, 16-21. [CrossRef]

32. Kovács, E.; Kelemen, E.; Kiss, G.; Kaloczkai, A.; Fabok, V.; Mihok, B.; Bela, G. Evaluation of participatory planning: Lessons from Hungarian Natura 2000 management planning processes. J. Environ. Manag. 2017, 204, 540-550. [CrossRef] [PubMed]

33. Primmer, E.; Kyllönen, S. Goals for public participation implied by sustainable development, and the preparatory process of the Finnish National Forest Programme. For. Policy Econ. 2006, 8, 838-853. [CrossRef]

34. Brescancin, F.; Dobšinská, Z.; De Meo, I.; Šálka, J.; Paletto, A. Analysis of stakeholders' involvement in the implementation of the Natura 2000 network in Slovakia. For. Policy Econ. 2018, 89, 22-30. [CrossRef]

35. Rowe, G.; Frewer, L.J. Public participation methods: A framework for evaluation. Sci. Technol. Hum. Values 2000, 25, 3-29. [CrossRef]

36. Boh, T. Shielding Implementation from Politicisation? Implementation of the Habitats Directive in Slovenia; OEUE Phase II, Occasional Paper; Dublin European Institute: Dublin, Ireland, 2004.

37. Gallo, M.; Malovrh, Š.P.; Laktić, T.; De Meo, I.; Paletto, A. Collaboration and conflicts between stakeholders in drafting the Natura 2000 Management Programme (2015-2020) in Slovenia. J. Nat. Conserv. 2018, 42, $36-44$. [CrossRef]

38. Hlad, B.; Kline, M. Natura 2000. Končno Poročilo o Izvajanju Komunikacijske Strategije. Priloga 10: Priporočila za Upravljanje in Komuniciranje Natura 2000; Ministry of the Environment and Spatial Planning: Ljubljana, Slovenia, 2004.

39. Nastran, M.; Pirnat, J. Stakeholder participation in planning of the protected natural areas: Slovenia. Sociologija i Prostor Časopis za Istraživanje Prostornoga i Sociokulturnog Razvoja 2012, 50, 141-164. [CrossRef]

40. Bibič, A.; Ogorelec, B.; Podobnik, J.; Mikuletič, J.; Vaupotič, M.; Bedjanič, M.; Midžić, Z.; Trebar, B. Natura 2000 Site Management Programme: 2007-2013 Operational Programme; Ministry of the Environment and Spatial Planning: Ljubljana, Slovenia, 2007; Volume 61.

41. Management of State Forests Act. In Official Gazette of the Republic of Slovenia; No. 9/16 of 12 February 2016; Ljubljana City Library: Ljubljana, Slovenia, 2016.

42. Dryzek, J.S. Deliberative Democracy and Beyond. Liberals, Critics, Contestations; Oxford University Press: Oxford, UK, 2000; p. 195. ISBN 0198295073, 9780198295075.

43. Smith, L.G. Impact Assessment and Sustainable Resource Management; Longman: Harlow, UK, 1993.

44. Healey, P. Collaborative Planning: Shaping Places in Fragmented Societies; Macmillan: London, UK, 1997; ISBN 1403949204, 9781403949202.

45. Innes, J. Consensus building: Clarification for the critics. Plan. Theory 2004, 3, 5-20. [CrossRef]

46. Webler, T.; Tuler, S.; Krueger, R. What is good participation process? Five perspectives from the public. Environ. Manag. 2001, 27, 435-450. [CrossRef]

47. Mascarenhas, M.; Scarce, R. The Intention Was Good: Legitimacy, Consensus Based Decision Making, and the Case of Forest Planning in British Columbia, Canada. Soc. Nat. Resour. 2004, 17, 17-38.

48. McGurk, B.; Sinclair, A.; Diduck, A. An assessment of stakeholder advisory committees in forest management: Case studies from Manitoba, Canada. Soc. Nat. Resour. 2006, 19, 809-826. [CrossRef]

49. Luyet, V.; Schlaepfer, R.; Parlange, M.B.; Buttler, A. A framework to implement Stakeholder participation in environmental projects. J. Environ. Manag. 2012, 111, 213-219. [CrossRef] [PubMed] 
50. Ritchie, J.; Lewis, J. (Eds.) Qualitative Research Practice: A Guide for Social Science Students and Researchers; SAGE Publications Ltd.: London, UK, 2003; ISBN 0761971092.

51. Creative Research Systems: Sample Size Calculator. Available online: https:/ /www.surveysystem.com/ sscalc.htm (accessed on 11 September 2018).

52. Dillman, D.A. Mail and Internet Survey: The Tailored Design Method, 2nd ed.; John Wiley \& Sons: Hoboken, NJ, USA, 2007; ISBN 978-0471323549.

53. Field, A. Discovering Statistics Using SPSS, 3rd ed.; Sage Publications Ltd.: London, UK, 2009; p. 857.

54. PUN 2000. Life + Management. Available online: http://www.natura2000.si/en/life-management/ (accessed on 18 August 2018).

55. Sotirov, M.; Lovric, M.; Winkel, G. Symbolic transformation of environmental governance: Implementation of EU biodiversity policy in Bulgaria and Croatia between Europeanization and domestic politics. Environ. Plan. C Gov. Policy 2015, 33, 986-1004. [CrossRef]

56. Ferranti, F.; Turnhout, E.; Beunen, R.; Behagel, J.H. Shifting nature conservation approaches in Natura 2000 and the implications for the roles of stakeholders. J. Environ. Plan. Manag. 2014, 57, 1642-1657. [CrossRef]

57. Kangas, A.; Heikkilä, J.; Malmivaara-Lämsä, M.; Löfström, I.; Case, P. Evaluation of a participatory urban forest planning process. For. Policy Econ. 2014, 45, 13-23. [CrossRef]

58. Domínguez, G.; Tena, J. Monitoring and evaluating participation in national forest programmes. The Catalan case. Schweizerische Zeitschrift fur Forstwesen 2006, 157, 438-444. [CrossRef]

59. Turnhout, E.; Behagel, J.; Ferranti, F.; Beunen, R. The construction of legitimacy in European nature policy: Expertise and participation in the service of cost-effectiveness. Environ. Politics 2015, 24, 461-480. [CrossRef]

60. Eben, M. Public participation during site selections for Natura 2000 in Germany: The Bavarian case. In Stakeholder Dialogues in Natural Resources Management; Stollkleemann, S., Welp, M., Eds.; Springer: Berlin/Heidelberg, Germany, 2006; pp. 261-278, ISBN 978-3-540-36916-5.

61. Kluvánková-Oravská, T.; Chobotová, V.; Banaszak, I.; Slavikova, L.; Trifunovova, S. From government to governance for biodiversity: The perspective of central and Eastern European transition countries. Environ. Policy Gov. 2009, 19, 186-196. [CrossRef]

62. Lecomte, N.; Martineau-Delisle, C.; Nadeau, S. Participatory requirements in forest management planning in Eastern Canada: A temporal and interprovincial perspective. For. Chron. 2005, 81, 398-402. [CrossRef]

63. Gane, M. Forest Strategy: Strategic Management and Sustainable Development for the Forest Sector; Springer: Godalming, UK, 2007; ISBN 9781402059643.

64. Geitzenauer, M.; Hogl, K.; Weiss, G. The implementation of Natura 2000 in Austria-A European policy in a federal system. Land Use Policy 2016, 52, 120-135. [CrossRef]

65. Weber, N. Participation or involvement? Development of forest strategies on national and sub-national level in Germany. For. Policy Econ. 2017, 89, 98-106. [CrossRef]

66. Hogl, K.; Kvarda, E. The Austrian Forest Dialogue: Introducing a New Mode of Governance Process to a Well Entrenched Sectoral Domain; InFER, University of Natural Resources and Applied Life Sciences: Vienna, Austria, 2008.

(C) 2018 by the authors. Licensee MDPI, Basel, Switzerland. This article is an open access article distributed under the terms and conditions of the Creative Commons Attribution (CC BY) license (http://creativecommons.org/licenses/by/4.0/). 